\title{
In-vitro and in-vivo Sunscreen Activity of Active Compounds Isolated from Fruits of Phaleria marcocarpha (Scheff.) Boerl
}

\author{
Aprilita Rina Yanti Eff*, Ratih Dyah Pertiwi, Irvani Rakhmawati, Tyas Putri Utami \\ Department of Pharmacy, Faculty of Health Sciences, Universitas Esa Unggul, INDONESIA.
}

\begin{abstract}
Objective: Mahkota dewa fruits (Phaleria marcocarpha (Scheff.) Boerl) have been found to contain benzophenone and xanthone derivatives which have a protective effect against ultraviolet light. This study was aimed to evaluate the sunscreen activities of mahkoside $A$, mangiferin and 6, 4-dihydroxy4-methoxybenzophenone-2-O- $\beta$-D-glucopyranoside (6, 4-DHMP) isolated from Mahkota dewa fruits in-vitro and in-vivo. Methods: In-vitro sunscreen activity was evaluated using spectrophotometric method by measuring percentage transmission of erythema, percentage transmission of pigmentation and sun protection factor (SPF). The sunscreen activity assays in-vivo was conducted by observing the effect of erythema in rats after exposed to an exotera lamp for $24 \mathrm{~h}$. Results: In-vitro assays showed that mahkoside A, mangiferin and 6, 4-dihydroxy-4-methoxybenzophenone-2-O- $\beta$-Dglucopyranoside at a concentration of $100 \mathrm{ppm}$ had SPF value of 3.44 , 2.82 and 3.08 respectively. In-vivo test results showed that mangiferin at concentrations of $12.5 \%, 25 \%$, and $50 \%$ decreased the amount of erythema
\end{abstract}

and erythema diameter significantly different than negative control ( $p$ $<0.05)$. Conclusion: Mahkoside A, mangiferin and 6, 4-DHMP possessed sunscreen activity in-vitro and in-vivo.

Key words: Mahkoside A, Mangiferin, 6, 4-dihydroxy-4-methoxybenzophenone-2-O- $\beta$-d-glucopyranoside, Phaleria marcocarpha, SPF, Erythema.

Correspondence

Aprilita Rina Yanti Eff, Department of Pharmacy, Faculty of Health Sciences, Universitas Esa Unggul, INDONESIA.

Phone: +62-215674223

Email: aprilita.rinayanti@esaunggul.ac.id

DOI: 10.5530/jyp.2018.2s.21

\section{INTRODUCTION}

Indonesia is geographically located in tropical climates, where the amount of solar radiation that reaches the surface of the earth is very abundant. ${ }^{1}$ In addition to beneficial to health in mediating the synthesis of vitamin $\mathrm{D}$ and endorphins in the skin, UV radiation also has a detrimental effect, especially the ultraviolet radiation with a wavelength of 290-400 nm. ${ }^{2}$

Excessive exposure of UV radiation to the skin causes adverse effects such as erythema, pigmentation, and premature aging. The reaction of erythema or sunburn on the skin arise as a result of ultraviolet radiation at a wavelength of 290-320 $\mathrm{nm}$ (UV-B), while the ultraviolet radiation at a wavelength of 320-400 nm (UV-A) causing darkness on the skin. ${ }^{3}$ The degree of skin damage depends on the frequency and duration of UV rays that affect the skin, excessive exposure causes the natural protection system is not able to withstand the radiation, so additional protection is required, among others, using sunscreen preparations. ${ }^{4}$ The sunscreen is a dosage form such as cream, moisturizers, lotion, shampoo or gel which contains a compound that is capable of absorbing or reflecting ultraviolet radiation from the sun, thus reducing the energy of radiation that penetrates into the skin and prevent damage to skin. ${ }^{5}$ Currently, the development of sunscreen preparations using natural ingredients takes precedence because of the assumption in the community that the natural materials are safer to use and have a mild negative impact. ${ }^{6}$

Natural materials that have the potential as sunscreen ingredients are Mahkota Dewa (Phaleria marcocarpha (Scheff.) Boerl. Mahkota Dewa is an original plant from Indonesia, which has long been used as a medicines for various types of diseases such as cancer, liver disorders, heart disease, diabetes, arthritis, kidney disorders, stroke, and hypertension. This plant contains alkaloids, saponins, polyphenols, phenolic glycosides such as mahkotaside, mangiferin, kaempferol-3-O- $\beta$-D- glucoside, dodecanoic acid, palmitic acid, ethyl stearate, and sucrose. ${ }^{7-8}$ Mahkota dewa also contains benzofenon derived compounds that have activity as sunscreen. ${ }^{9}$ Study conducted by Zulkarnain, et al. (2015) showed that the preparations of cream and lotion containing ethanol extract of mahkota dewa have the ability as a sunscreen in-vitro. ${ }^{10}$ Physical stability of topical and sunscreen activity of o/w cream of ethanolic extract of mahkota dewa fruit has studied by Shovyana and Zulkarnaen using mice showed that cream Mahkota dewa at concentration 4.6, $\mathrm{d}$ and 10\% have an activity as a sunscreen with an SPF value of $1.25 ; 1.56 ; 2.4$; and 3.05 and have a good physical stability during storage. ${ }^{9}$

Benzophenone derivatives from Mahkota dewa have a protective effect against the dangers posed by UV radiation. ${ }^{9}$ Benzophenone and xanthone derived compounds present in Mahkota dewa fruits are mahkoside A, mangiferin and 6,4-dihydroxy-4-methoxybenzophenone-2-O- $\beta$-Dglucopyranoside (6,4-DHMP). ${ }^{11}$ Benzophenones are compounds that are often present in sunscreen formulations such as creams, gels and lotions. The ability of benzophenone derivatives as an absorber of UV light is used among others as photoinisiators in variety of polymers and as sunscreen compounds, one of which can be used to prevent damage of smell and colors on products such as perfume, soap and food wrappers. ${ }^{12}$ Sunscreen serves as a protective agent of the skin to excessive to excessive ultraviolet radiation. Sunscreen has ability to block UV induced sunburn. Sunscreen helps prevent sunburn and reduce the harmful effects of sunlight such as premature skin aging and skin cancer. The results of the in-vitro and in-vivo sunscreen test activity in animals and humans produce value sun protection factor (SPF) that reflects their ability to prevent sunburn. Sunscreen is found in cream, form of lotion, gel, stick, spray, and lip balm. ${ }^{13}$ Sunscreen contains one or several compounds that act as filters against UV radiation exposed to the epidermis. There are 
two types of sunscreen that is physical and chemical sunscreen the physical sunscreens reflect and spread UVB, UVA and visible radiation, while chemical sunscreens can absorb ultraviolet radiation and re-radiate chemical energy as heat or light. Some synthetic sunscreen present on the market can have adverse effects on human skin, such as photon reactions, photosensitization, and contact dermatitis. Nowadays, searching natural sunscreen that acts as photo protective agent being conducted in order to have a safe sunscreen. ${ }^{14}$

The effectiveness of sunscreen preparation is expressed by SPF (Sun Protected Factor) value. SPF is a universal indicator that describes the effectiveness of a UV protector product or substance. The higher SPF value of a product, the more effective sunscreen to protect skin from the harmful effects of UV light. ${ }^{15}$ SPF can be interpreted as the amount of UV energy required to cause MED (Minimal Erytemal Dose) on skin protected sunscreen active ingredient compared with the amount of energy required to cause the MED without sunscreen protection. ${ }^{16}$ Evaluation of the effectiveness of a sunscreen preparation can be done using two methods, the in-vivo and in-vitro. In-vitro measurements were performed indirectly using spectrophotometric methods while in-vivo measurements carried out directly on the skin of animals or some individuals voluntarily. ${ }^{15}$ This study was conducted to assess whether mahkoside A, mangiferin and 6, 4-DHMP isolated from the fruit of the gods crown as a sunscreen activity in-vitro and in-vivo assay.

\section{MATERIALS AND METHODS}

\section{Materials}

Mahkoside A, mangiferin and 6, 4-DHMP isolated from Mahkota dewa fruits (Phaleria macrocarpha (scheff.) Boerl.), aqua distillata, dimethyl sulfoxide (Merck), methanol (Merck) and Oksibenzone (Sigma), Spectrophotometer (Thermo Scientific), calipers, exotera lamp.

\section{Methods \\ Isolation and characterization of isolates}

The sun-dried fruits of Mahkota dewa (6 kg) was crushed and macerated with methanol $80 \%(3 \times 24 \mathrm{~h})$ at room temperature, then the extracts were evaporated in rotary evaporator yield methanol extract. Furthermore, methanol condensed extract (1032 g) partitioned using hexane, after evaporated yield hexane fraction. The partition was continued by adding ethyl acetate to the methanol extracts. After removing of the solvent by rotary evaporator, the ethyl acetate fraction was chromatographed on silica gel using gradient solvent hexane, ethyl acetate, and methanol, respectively. The result of column fractionation is combined based on the TLC profile and after that the isolate were purified through the recrystallization process. The physicochemical data of isolate A then was taken, i.e. mass spectra, IR spectra with $\mathrm{KBr}$ pellets, UV spectra, $1 \mathrm{H}-, 13 \mathrm{C}$ - and 2D-NMR spectra and melting point. ${ }^{11,17}$

\section{In-vitro sunscreen activity}

\section{Determination of percent transmission of erythema (\%Te) and percent} transmission of pigmentation (\%Tp)

Mahkoside A, mangiferin and 6, 4-DHMP were each dissolved in dimethyl sulfoxide to obtain concentrations of 1000, 750, 500, 250 and $100 \mu \mathrm{g} / \mathrm{ml}$. For determination of $\% \mathrm{~T}$ erythema and $\% \mathrm{~T}$ pigmentation, scanning spectra of the samples in solution were obtained by running from 372.5 to $292.5 \mathrm{~nm}$ (at five nm intervals) and 337.5 to 322.5 , respectively. The value of absorbance is converted to transmittance percent. \% Te and \% Tp were calculated using Cumpelix equation (Cumpelix, 1972) i.e. and . Te and $\mathrm{Tp}$ can determine the sunscreen category i.e. as sunblock ( $\% \mathrm{Te}<1$ and $\% \mathrm{Tp} 3-40)$, extra protection (Te\% 1-6 and $\% \mathrm{Tp} 42-86)$, suntan (\% Te $6-12$ and $\%$ Tp 45-86), and tanning (Te\% 10-18 and\% Tp 45-86). ${ }^{18}$

\section{Determination of Sun Protecting Factor (SPF)}

Mahkoside A, mangiferin, 6, 4-DHMP and oxibenzone were dissolved in dimethyl sulfoxide to obtain a concentration of 1000, 750, 500, 250 and $100 \mu \mathrm{g} / \mathrm{ml}$. Scanning spectra of the samples in solution were obtained by running from 320 to $290 \mathrm{~nm}$ at five nm intervals. The SPF value is calculated using the Mansur equation as follows:

$$
S P F_{\text {spectrophotometer }}=C F \times \sum_{290}^{320} E E(\Lambda) \times I(\Lambda) \times A b s(\Lambda),
$$

where EE = Spectrum of erythemal effects; I = Intensity of light spectrum; Abs $=$ absorption of sunscreen products; $\mathrm{CF}=$ Correction factor. ${ }^{19}$

\section{In-vivo sunscreen activity}

\section{Animal and study design}

Twenty five rats aged 12-16 weeks were chosen and randomly divided into five groups, each group consisted of 5 rats. The group was divided as follows: negative control group (given DMSO), positive control group (given oxibenzon), experiment group 1-3 (given isolate at a concentration of 12.5, 25 and 50\%). Prior study approval was obtained from the Ethics Committee Medical Faculty of Universitas Indonesia (No. 160/UN2.F1/ ETIK/2017). All animal management and procedures were performed in accordance with the recommended guidelines. The rats were kept in stainless-steel cages and maintained at room temperature of $27 \pm 2^{\circ} \mathrm{C}$ with a $12 \mathrm{~h}$ light-dark cycle. All rats had free access to food and water ad libitum during the study period. Each tested rat's back was shaved on the day prior to an experiment. Test compound was administered on such a site $\left(\approx 1 \mathrm{~g} / 1.33 \mathrm{~cm}^{2}\right)$. After $1 \mathrm{~h}$ contact with the test compound, the rats were exposed to an exotera lamp for $24 \mathrm{~h}$. Further diameter of erythema was measured using a caliper. Erythema score was calculated using a scale of $0-4$. Score $0=$ no erythema; score $1=$ very little erythema (diameter $\leq 25.00 \mathrm{~mm}$ ); score $2=$ clearly defined erythema (diameter between $25.10-30.00 \mathrm{~mm}$ ); score $3=$ moderate to severe erythema (diameter between $30.10-35.00 \mathrm{~mm}$ ); score $4=$ shaping crust (diameter $\geq 35){ }^{20}$

\section{Data analysis}

Data from in-vitro assay were analyzed by observing the values of $\% \mathrm{Tp}$. The compound has activity as sunscreen when $\% \mathrm{Te}<18 \%, \% \mathrm{Tp}<86 \%$ and SPF value $>2(2,14)$. The data obtained from in-vivo assay were presented in tabular form. Data were analyzed with ANOVA using SPSS 20 for windows.

\section{RESULTS}

\section{Characteristic of isolates}

The result of extraction of $6 \mathrm{~kg}$ of powdered fruits of mahkota dewa using $80 \%$ methanol yield $1032 \mathrm{~g}$ of dense methanol extract. Liquid-liquid fractionation to methanol condensed extract using hexane and ethyl acetate solvents resulted in a yield of $3.01 \%$ and $17.11 \%$, respectively. Chromatographic column of 17, $20 \mathrm{~g}$ extract from ethyl acetate fraction with silica gel as stationary phase and mobile phase using hexane, ethyl acetate and methanol, starting from $100 \%$ hexane to $100 \%$ methanol yielding 82 fraction, then fractions having chromatogram profile the same is combined and obtained 7 fractions, namely Fractions A, B, C, D, $\mathrm{E}, \mathrm{F}$ and $\mathrm{G}$. Recrystallization was carried out on fraction having weight more than $100 \mathrm{mg}$, that are F and G fraction. From fraction F obtained by 2 isolate, ie isolate 1 obtained as much as $317,1 \mathrm{mg}$ and isolate 2 as much as $383,2 \mathrm{mg}$. While the fraction of $\mathrm{G}$ obtained 1 isolate, that is isolate 3 as much as $217,7 \mathrm{mg}$. The result of structural elucidation indicates that isolate 1 is a compound of 6,4'-dihydroxy-4-methoxybenzo-mono-2-O-D-glucopyranoside (6,4-DHMP) with molecular weight $[\mathrm{M}+]=422,43$ and molecular formula $\mathrm{C}_{20} \mathrm{H}_{22} \mathrm{O}_{10}$. Isolate 2 is a mahkoside A (4, 4'-dihydroxy-6-methoxybenzylamine) with molecular weight $\mathrm{m} / \mathrm{z}$ 
$445[\mathrm{M}+23(\mathrm{Na})]$ with the molecular formula $\mathrm{C}_{20} \mathrm{H}_{22} \mathrm{O}_{10}$, and isolate 3 is mangiferin with molecular weight $\mathrm{m} / \mathrm{z} 445[\mathrm{M}+23(\mathrm{Na})]$ with molecular formula $\mathrm{C}_{19} \mathrm{H}_{18} \mathrm{O}_{11} \cdot{ }^{11}$

\section{In-vitro sunscreen activity}

Te and Tp of oxibenzone, mahkoside A, mangiferin and 6, 4-dihydroxy4-methoxybenzo-benzide are shown in Figures 1 and 2.

\section{Sun Protection Factor (SPF) value}

SPF value measurement result and the protected categories of oxibenzone, mahkoside A, mangiferin and 6, 4-dihydroxy-4-methoxybenzophenone2-O- $\beta$-D-glucopyranoside are shown in Table 1.

\section{In-vivo sunscreen activity \\ Erythema reaction}

Diameters of erythema $(\mathrm{mm})$ due to treatment with oxibenzones, mahkoside A, mangiferin and 6, 4-DHMP are presented in Figure 3.

\section{Score of erythema}

\section{Scores of erythema are shown in Table 3.}

Statistical test results show that there were a significant difference in diameter of erythema between DMSO with oxibenzone, mahkoside A $50 \%$, mangiferin 25\%, mangiferin 50\%, and 6, 4-DHMP 12, 5\%, 25\% and $50 \%$. There were no significant difference between oxybenzone and mahkoside A 25\% and 50\%; mangiferin 12.5\%, 25\% and 50\%, and 6, 4-DHMP 25\% and 50\%.

\section{DISCUSSION}

The skin serves as the main barrier between the body and the environment against a variety of agents, both physical and chemical that can cause

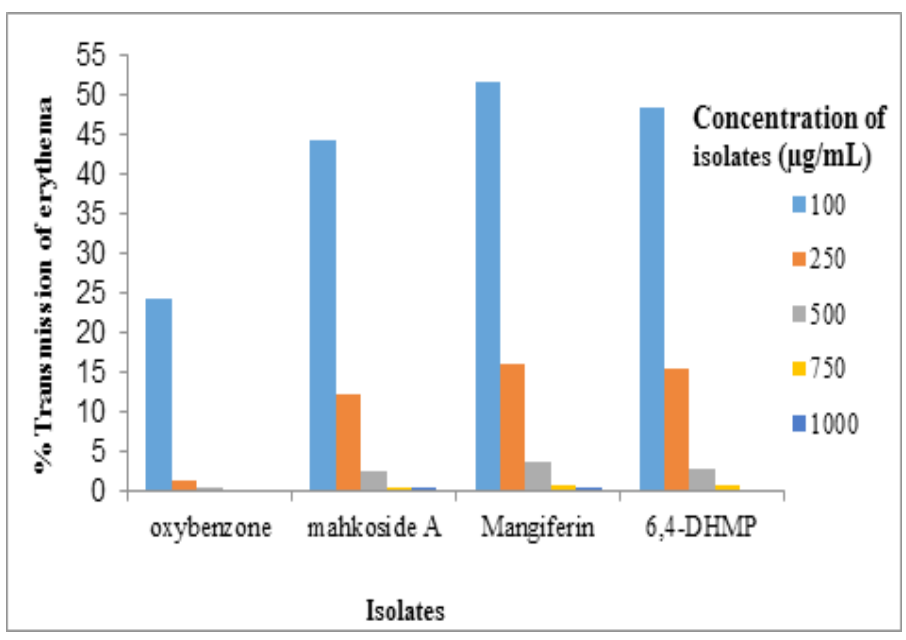

Figure 1: Percentage transmission of erythema of oxibenzone and isolates.
Table 1: SPF value of oxibenzone and isolates.

\begin{tabular}{|c|c|c|c|c|c|}
\hline \multirow{2}{*}{ Isolate } & \multicolumn{5}{|c|}{ Concentration $(\mu \mathrm{g} / \mathrm{ml})$} \\
\hline & 100 & 250 & 500 & 750 & 1000 \\
\hline Oxibenzone & 6,0142 & 19,2914 & 33,0845 & 48,3210 & 63,9032 \\
\hline Mahkoside A & 3,4362 & 10,0447 & 17,2021 & 31,5842 & 34,5089 \\
\hline Mangiferin & 2,8255 & 7,2576 & 15,8372 & 21,6781 & 27,8173 \\
\hline $\begin{array}{c}\text { 6,4-Dihydroxy-4- } \\
\text { methoxybenzophenone- } \\
\text { 2-O- } \beta \text {-D- } \\
\text { glucopyranoside }\end{array}$ & 3,0788 & 8,1277 & 16,1140 & 22,6914 & 29,2071 \\
\hline
\end{tabular}

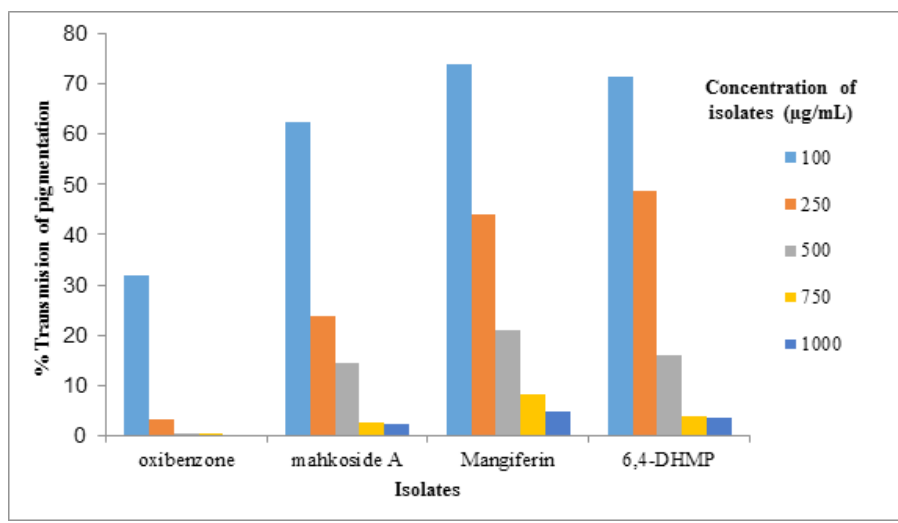

Figure 2: Percentage transmission of pigmentation of oxibenzone and isolates.

damage to skin tissue. Skin damage can occur due to the presence of ultraviolet light components from sunlight reaching the earth. ${ }^{3}$ Sunscreen is a compound that can protect the skin from the effects of ultraviolet light (UV) rays emitted from the sun. UV A (320-400 nm) and UV B (290-320 nm) light can cause irreversible skin damage such as cancer, hyperpigmentation and aging. The use of sunscreen can protect the skin from damage, therefore it is necessary to search for natural ingredients from plants that can counter the adverse effects of sunlight. Natural sunscreens generally contain antioxidants such as polyphenols, flavonoids and carotenoids that can minimize the effects of free radicals contained in UV light. ${ }^{15,21}$ The effectiveness of sunscreen can be measured by in-vitro and in-vivo assay. In-vitro assays are performed indirectly with samples while in-vivo are performed directly on the skin of animals or humans. ${ }^{22} 26$ In this study, sunscreen activity was assessed by \%Te, \% Tp and SPF values. Measurements of the activity of mahkoside A, mangiferin and 6, 4-DHMP were performed using oxybenzone and DMSO as comparators. Oxybenzone is a chemical sunscreen of benzophenone group that can absorb UVA and UVB light so often used in sunscreen formulations. ${ }^{23}$

Table 2: Protection categories based on SPF values.

\begin{tabular}{|c|c|c|c|c|c|}
\hline \multirow{2}{*}{ Isolate } & \multicolumn{5}{|c|}{ Concentration $(\mu \mathrm{g} / \mathrm{ml}) /$ protection category } \\
\hline & 100 & 250 & 500 & 750 & 1000 \\
\hline Oxibenzones & Extra Protection & Ultra protection & Ultra protection & Ultra protection & Ultra protection \\
\hline Mahkoside A & Minimal protection & Maximal protection & Ultra protection & Ultra protection & Ultra protection \\
\hline Mangiferin & Minimal protection & Minimal protection & Ultra protection & Ultra protection & Ultra protection \\
\hline $\begin{array}{l}\text { 6,4-Dihydroxy-4-methoxybenzophenone-2-O- } \beta \text {-D- } \\
\text { glucopyranoside }\end{array}$ & Minimal protection & Maximal protection & Ultra protection & Ultra protection & Ultra protection \\
\hline
\end{tabular}




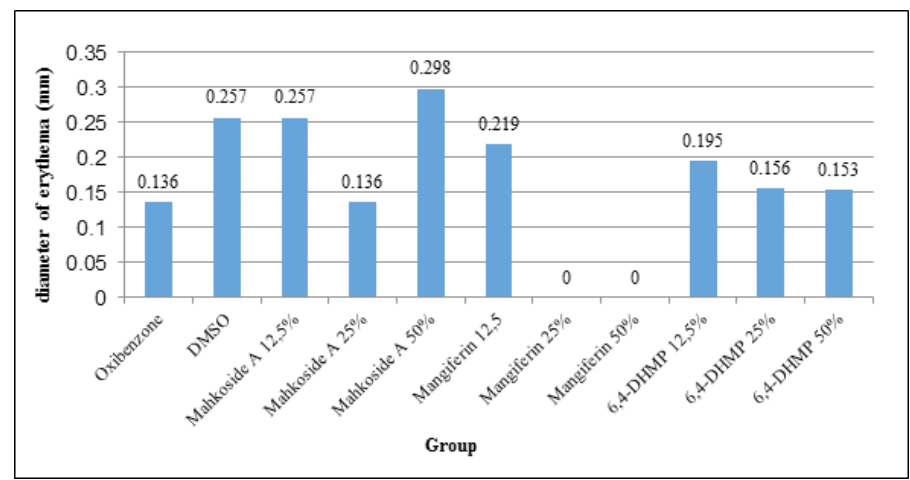

Figure 3: Diameter of erythema $(\mathrm{mm})$ from each rat group.

Table 3: Score of erythema.

\begin{tabular}{cc}
\hline Group & Score of erythema \\
\hline Oxibenzone & 1 \\
DMSO & 1 \\
Mahkoside A 12,5\% & 1 \\
Mahkoside A 25\% & 1 \\
Mahkoside A 50\% & 1 \\
Mangiferin 12,5\% & 1 \\
Mangiferin 25\% & 0 \\
Mangiferin 50\% & 0 \\
6,4-dihydroxy-4-methoxybenzophenone-2-O- $\beta$-D- \\
glucopyranoside 12.5\%
\end{tabular}

The concentrations of material test used in this study were 100; 250; 500; 750 ; and $1000 \mu \mathrm{g} / \mathrm{mL}$. The selection of concentrations is based on optimization results as well to see the effect of increased isolate concentration on sunscreen activity. The percent value of erythema transmission (\% Te) as well as the percentage of pigmentation transmission (\% Tp) show that the greater the concentration of the isolates of mahkoside A, mangiferin and 6, 4-DHMP, the smaller \% Te and \% Tp. This show that all of isolates are able to absorb UV light strongly and reduce the amount of exposure received by the skin.

Table 2 shows the protection categories of all three isolates. From Table 2 it is seen that at the consentration of $100 \mathrm{ppm}$ the three isolates have minimal protection category, at the concentration of $250 \mathrm{ppm}$ have maximum protection category, except mangiferin at this concentration the categorization is minimal protection, and at the concentration of $500-1000 \mu \mathrm{g} / \mathrm{ml}$ has the ultra-protection category. As compare to the chemical standard sunscreen oxibenzone which showed that at consentration of $100 \mu \mathrm{g} / \mathrm{ml}$ has extra protection category and at concentration of $250-1000 \mu \mathrm{g} / \mathrm{ml}$ have ultra-protection category. From the measurement of SPF values showed that the mahkoside A, mangiferin and 6,4-DHMP at concentrations of $100,250,500,750$, and $1000 \mu \mathrm{g} / \mathrm{ml}$ had a protective effect as sunscreen with SPF values of 2.8 to 34.5. A substance can provide a protective effect as a sunscreen if its SPF value is more than $2 .{ }^{24} \mathrm{SPF}$ can be determined by value the energy ratio of the exposed UV light to cause erythema and can also through the time it takes to emerge erythema. ${ }^{25}$

European Commission (EC) Recommendation in Osterwalder and Herzog (2009) classified SPF value are as the following: SPF 6-10 (low protection), SPF 15-25 (protection), SPF 30-50 (high protection), SPF $50+$ value (very high protection). ${ }^{26}$ The higher the desired SPF value, the higher the amount of active sunscreen ingredient needed. ${ }^{26}$

Results of in-vivo study showed that there were no significant difference between oxybenzone and mahkoside A $25 \%$ and 50\%; mangiferin $12.5 \%$, $25 \%$ and $50 \%$, and 6, 4-DHMP $25 \%$ and $50 \%$. No erythema showed in mangiferin at concentration of $25 \%$ and $50 \%$. From table 3, it seen that three isolates have score erythema 1 very little erythema (diameter $\geq 25.00 \mathrm{~mm}$ ), except mangiferin at concentration of $25 \%$ and $50 \%$ have score 0 (no erythema).

In-vivo sunscreen activity was performed on the basis of anti-inflammatory properties of a compound measured by a score of $0-4$ in areas of the skin that respond to erythema. In this study more emphasis on the effects of erythema to determine the effect of sunscreen protection on the skin. UV Exotera lamp has the same wavelength as UV-B light with wavelength 290-320 nm. UV-B rays can cause tanning, burning skin (sunburn), and the formation of skin cancer. Despite the amount of UV-A received earth is $10 \%$ more than UV-B, but more erythema production is caused by UV-B. Erythema also caused by the dilatation of arteries and veins in the lining dermis, so the skin color looks reddish and visible on the surface of the skin or membrane. ${ }^{22}$

Mahkota Dewa (Phaleria macrocarpa (Scheff.) Boerl) is one of the medicinal plant which grows in Indonesia. The ethyl acetate of mahkota dewa fruits which was isolated by silica gel column chromatography gave benzophenone glucoside of mahkoside A, mangiferin and 6,4-DHMP. ${ }^{11}$ These compound have antioxidant activity. ${ }^{27}$ The main factor of skin damage is free radicals. To stimulate the skin to repair and build itself naturally, potent antioxidants are needed. Powerful antioxidants protect humans from oxidative stress. Some natural ingredients have antioxidant activity and are able to resist oxidative damage to the skin due to free radicals. ${ }^{28}$ Mangiferin (1,3,6,7-tetrahydroxyxanthone-C(2)- $\beta$-D-glucoside) is a xanthone glucoside which is abundantly found in fruit, leaves and stem bark of Phaleria macrocarpa and Mangifera indica. Its exhibits several beneficial pharmacological effect on inflammation, oxidative injury, tumor growth, microorganism infections, metabolic regulations, immune regulations, and radioprotection. ${ }^{29}$

\section{CONCLUSION}

Mahkoside A, mangiferin and 6, 4-dihydroxy-4-methoxybenzophenone2-O- $\beta$-D-glucopyranoside isolated from Mahkota Dewa (Phaleria macrocarpa (Scheff.) Boerl) have sunscreen activity in-vitro and in-vivo.

\section{ACKNOWLEDGEMENT}

This research was funded by grant from Indonesia Ministry of Research, Technology and Higher Education.

\section{CONFLICT OF INTEREST}

The authors declare no conflict of interest.

\section{ABBREVIATIONS}

UV: ultra violet; SPF: sun protection factor; 6,4-DHMP: 6, 4-dihydroxy4-methoxybenzophenone-2-O- $\beta$-D-glucopyranoside; MED: minimal erytemal dose; TLC: thin layer chromatography; IR: infra red; NMR: nuclear magnetic resonance; Te: transmission of erythema; Tp: transmission of pigmentation; DMSO: dimethyl sulfoxide.

\section{REFERENCES}

1. Winarso PA. Indonesia solar power study using secondary data. Climatol Weather Forecasting. 2017;5(1):1-5.

2. Zulkarnain AK, Ernawati N, Sukardani NI. Activities of yam starch (Pachyrizus 
erosus (L.) Urban) as sunscreen in mouse and the effect of its concentration to viscosity level. Trad Med J. 2013;18(1):5-11.

3. D'Orazio J, Jarrett S, Amaro-Ortiz A, Scott T. UV radiation and the skin. Int J Mol Sci. 2013;14(6):12222-48.

4. Lintner K. Benefits of anti-aging actives in sunscreens. Cosmetics. 2017;4(1):7.

5. Kantivan P, Samant M, Srivastava R. Natural sunscreen agents: a review. Sch Acad J Pharm. 2013;2(6):458-63.

6. Buddepu M, Sabithadevi K, Ashok V, Ramprasad MV. Determination of sunscreen activity of Pongamia pinnata (L) essential oils. Drug Invent Today. 2011;38(8):197-9.

7. Sumastuti R. Research against leaves and fruit crown god. One day seminar mahkota dewa. Jakarta: Center for Research and Development of Pharmaceutical and Traditional Medicine, Ministry of Health of the Republic of Indonesia. 2003.

8. Oshimi S, Zaima K, Matsuno Y, Hirasawa Y, lizuka T, Studiawan H, et al. Studies on the constituents from the fruits of Phaleria macrocara. J Nat Med. 2008; 62(2):207-10.

9. Shovyana HH, Zulkarnain AK. Physical stability and activity of cream W/O etanolic fruit extract of mahkota dewa as a sunscreen. Trad Med J. 2013;18(2).

10. Zulkarnain AK, Marchaban M, Wahyuono S, Susidarti RA. Sun protector factor (SPF) in-vitro and the physical stability of o/w cream optimal formula from the partition product of mahkota dewa leaves (Phaleria macrocarpa (scheff) boerl). Ind J Pharm. 2015;26(4):210-8.

11. Rinayanti A. Studi efek antihipertensi sepuluh simplisia dari sembilan tanaman obat Indonesia fokus pada penghambat enzim konversi angiotensin (EKA). Doctoral dissertation, Faculty of Pharmacy, University of Indonesia, Depok, Indonesia. 2014.

12. Calafat AM, Wong $L Y, Y e X$, Reidy JA, Needham LL. Concentrations of the sunscreen agent benzophenone-3 in residents of the United States: National Health and Nutrition Examination Survey 2003-2004. Environ Health Perspect. 2008;116(7):893-7.

13. Kantivan P, Samant M, Srivastava R. Natural sunscreen agents: A review. Sch Acad J Pharm. 2013;2(6):458-63.

14. Saewan N, Jimtaisong A. Photoprotection of natural flavonoids. J Appl Pharm Sci. 2013;3(9):129-41.

15. Dutra EA, Oliveira DA, Kedor-Hackmann ER, Santoro MI. Determination of sun protection factor (SPF) of sunscreens by ultraviolet spectrophotometry. Brazilian J Pharm Sci. 2004;40(3):381-5.

16. Food, Drug Administration. The United States Pharmacopeia, $32^{\text {th }}$ Edition. USA. 2009.

17. Winarno $\mathrm{H}$, Katrin, WE. Benzophenone glucoside isolated from the ethyl acetate extract of the bark of mahkota dewa (Phaleria macrocarpa (scheff.) boerl) and its inhibitory activity on leukemia I1210 cell line. Indo J Chem. 2009;9(1):142-5.

18. Cumpelik BM. Analytical procedure and evaluation of sunscreen. J Soc Cosmet Chem. 1972;23(6):333-45

19. Mansur JS, Breder MN, Mansur MC, Azulay RD. Determination of sun protection factor for spectrophotometry. An Bras Dermatol. 1986;61:121-4.

20. Ou-Yang H, Rzendzian RB. Sunburn protection by sunscreen sprays at beach. Cosmetics. 2017:4(1):10.

21. Cefali LC, Ataide JA, Moriel P, Foglio MA, Mazzola PG. Plant-based active photoprotectants for sunscreens. Int J Cosmet Sci. 2016;38(4):346-53.

22. Wolff K, Goldsmith L, Katz S, Gilchrest B, Paller AS, Leffell D. Fitzpatrick's dermatology in general medicine, 7th Edition. New York: McGraw-Hill. 2008.

23. Chisvert $A$, Balaguer $A$, Salvador $A$. Tanning and whitening agents in cosmetics. Regulatory, aspects and analytical methods. In: Salvador A, Chisvert A, Carreño AS Townshend A, Carreño AS, editor. Analysis of cosmetic products. Amsterdam Elsevier. 2007:128-40.

24. Lourith N, Kanlayavattanakul M, Chingunpitak J. Development of sunscreen products containing passion fruit seed extract. Brazilian J Pharm Sci. 2014;53(1):1-8.

25. Draelos ZD, Thaman LA. Cosmetic formulation of skin care products. New York: Taylor and Francis Group. 2006:157-9.

26. Osterwalder U, Herzog B. European Commission recommendation on the efficacy of sunscreen products and the claims made relating thereto, 2006 Sun protection factors: worldwide confusion. Br J Dermatol. 2009;161(s3):3-24.

27. Susilawati, Matsjeh S, Pranowo HD, Anwar C. Antioxidant activity of 2,6,4'-trihydroxy-4-methoxy benzophenone from ethyl acetate extract of leaves of mahkota dewa (Phaleria macrocarpa (Scheff.) Boerl). Indo J Chem. 2011;11(2):180-5.

28. Anitha T. Medicinal Plants Used in Skin Protection. Asian J Pharm Clin Res. 2012;5(3):35-8

29. Wei ZQ, Deng JG, Yan L. Pharmacological Effects of Mangiferin. Chinese Herb Med. 2011;3(4):266-71.

Article History: Submission Date : 11-01-2018 ; Revised Date : 28-01-2018; Acceptance Date : 12-03-2018.

Cite this article: Eff ARY, Pertiwi RD, Rakhmawati I, Utami TP. In-vitro and in-vivo Sunscreen Activity of Active Compounds Isolated from Fruits of Phaleria marcocarpha (Scheff.) Boerl. J Young Pharm. 2018;10(2)Suppl:s106-s110. 